\title{
Preferences for Hereditary Breast and Ovarian Cancer Information among Mexican, Cuban and Puerto Rican Women at Risk
}

\author{
Gwendolyn P. Quinn ${ }^{a, b}$ Jessica Mclntyre ${ }^{b}$ Susan T. Vadaparampila, b \\ ${ }^{a}$ Department of Oncologic Sciences, University of South Florida College of Medicine, and ${ }^{b}$ Moffitt Cancer Center, \\ Health Outcomes and Behavior Program, Tampa, Fla., USA
}

\section{Key Words}

Hereditary breast and ovarian cancer, genetics $\cdot$ Hispanic

women • Qualitative research

\begin{abstract}
Background: Little is known about the preferences of at-risk Hispanic women to gain information on hereditary breast and ovarian cancer (HBOC). Aims: This study sought to qualitatively explore preferences for $\mathrm{HBOC}$ information among at-risk Mexican, Puerto Rican and Cuban women and to pilot a mock brochure aimed at Hispanic women. Methods: Hispanic women aged 18-65 years with a personal or family history of breast or ovarian cancer participated in a semistructured interview. Data were analyzed using a combination of open-coding and content analysis. Results: Fiftythree women participated in the study. For the majority of content areas, there were no major differences between the subethnicities. All women reported discussing cancer with a doctor after a family member had been diagnosed and discussing cancer within their families; however, the content of the discussion varied. Cuban and Puerto Rican women reported using the Internet routinely for health care information while Mexican women said they did not have access to computers and did not use them. All women liked the content and photos in the brochure but Mexican women thought the reading level was too high. Preferences for the
\end{abstract}

spokesperson focused on the need for Spanish-speaking health care providers. Conclusions: While the data show some similarities, such as patterns of cancer discussion and appreciation of the mock brochure, there were differences between the groups on information preferences. In designing $\mathrm{HBOC}$ education information for Hispanic audiences, it is important to consider varied channels for dissemination and preferences for specific types of information across subethnicities.

Copyright $\odot 2010$ S. Karger AG, Basel

\section{Introduction}

Hispanics are an ethnically and racially diverse group with origins in Mexico, the Caribbean, Central or South America and Spain [1]. Hispanics comprised $12.5 \%$ of the US population in the year 2000 and are expected to comprise $25 \%$ by 2050 . Three ethnic groups that comprise the majority of the US Hispanic population are Mexicans, Cubans and Puerto Ricans [2]. While national data on Hispanics tend to combine these groups, available data indicate that when disaggregated, each group is unique with regard to demographic, medical and cultural factors [2-7]. Mexicans are less likely to have health insurance or a high school education than Puerto Ricans and Cubans. However, Puerto Ricans are the most likely of the three

Susan T. Vadaparampil, PhD, MPH 12902 Magnolia Drive MRC-CANCONT

Tampa, FL 33612 (USA)

E-Mail karger@karger.ch_Accessible online at:

www.karger.com www.karger.com/phg 
groups to live below the poverty level [2]. Limited data suggest that Cubans may have higher rates of breast cancer incidence and mortality compared to Mexicans (data not available for Puerto Ricans) [5]. With regard to breast cancer screening, Cubans have 10\% lower mammography rates compared to Puerto Ricans and Mexican Americans [7]. In addition, recent evidence suggests that Hispanic women with a personal history of breast cancer have the highest prevalence rate of $B R C A 1$ mutations when compared to other minority racial/ethnic groups (i.e. African-American, Asian-American) in the USA [8].

As the Hispanic population is comprised of different subethnicities, each may also have diverse health needs and barriers to accessing health care. The perception of Hispanics as a homogeneous population lacking withingroup diversity could serve as a barrier to efforts aimed at providing appropriate care and health education to Hispanics [9]. The interrelationship between the variations in knowledge, attitudes and use of preventive screening among Hispanic subgroups is not altogether clear and requires further research [10-12]. Developing health education and informational materials for Hispanics as a homogeneous group may be a factor contributing to inequalities in the availability and use of health care services in this population [9].

The purpose of this study was to assess the preferences of Hispanic women for health education information concerning hereditary breast and ovarian cancer (HBOC). A secondary aim of the study was to examine if these preferences varied by Hispanic subethnicity, specifically Mexican, Puerto Rican and Cuban, the predominant Hispanic subgroups in Central Florida where the study was conducted.

\section{Methods}

\section{Design and Setting}

In preparation for the development of an intervention to increase awareness of HBOC genetic counseling and testing, we conducted qualitative interviews to understand the preferences of at-risk Hispanic women for health education information.

A cross-sectional design was employed, using sequential mixed qualitative and quantitative research methods. Eligible consenting women participated in an audio-taped semistructured, in-depth qualitative interview (fig. 1). The interview included reviewing a mock brochure designed to inform women about HBOC genetic counseling and testing (fig. 2). The brochure was in Spanish and English, and as with all aspects of the study, participants could select which language they preferred to view the pamphlet in. The brochure was designed at an 8 th-grade reading level and contained stock photos of Hispanic women. Following the interview, a brief battery of structured quantitative survey items for descriptive and exploratory purposes was administered. The sample size was based on estimates of the number needed for qualitative saturation $[13,14]$ rather than on statistical power calculations. After interviewing 46 participants for the main study, the investigators recognized that no new themes were emerging and that thematic saturation had been reached. It was decided that it would be useful to address specific elements of the mock educational brochure beyond color, font size, tone and photos. Five additional questions were added to aid in refining the brochure (fig. 1). Because we had met our accrual goal for Puerto Ricans, the evaluations of the brochure represent a subgroup of Cuban $(\mathrm{n}=2)$ and Mexican $(\mathrm{n}=5)$ participants who were recruited and interviewed with the additional interview questions added.

Participants were recruited after the project had received institutional review board approvals from the University of South Florida, and each participant provided written informed consent prior to participation. This paper focuses on the results from the qualitative interviews.

\section{Participant Recruitment and Data Collection}

Eligible participants were Hispanic women who (a) were between 18 and 65 years old, (b) identified themselves as Mexican, Puerto Rican or Cuban, (c) had a personal diagnosis of breast cancer prior to the age of 50 or had at least 1 first-degree relative (mother, sister, daughter) with a diagnosis of breast cancer prior to the age of 50 and/or ovarian cancer at any age, and (d) had not previously had genetic counseling and/or a genetic test for hereditary cancer. Participants were recruited by community-based methods including distributing flyers at local health department clinics serving Hispanic populations, Hispanic-owned businesses and organizations, health fairs and food pantries and press releases to local English and Spanish media outlets. All recruitment efforts, other than the press releases, utilized a bilingual-bicultural trained research assistant. The flyers were distributed in English and Spanish and included a brief description and purpose of the study, basic eligibility criteria and a telephone number for prospective participants to call with questions or to express interest in the study. Eligible, consenting women were interviewed in person in their preferred language and at a location selected by the participant. The research assistant read all study materials aloud to the respondent to minimize literacy issues. The interview took approximately $1 \mathrm{~h}$ to complete including reviewing the mock brochure. At the end of the interview, participants received a gift card of USD 40 to a local discount store.

\section{Measures}

The following sociodemographic and medical characteristics were assessed via a self-report questionnaire: age, ethnicity, marital status, number of children, education, employment status, insurance status, religion, income, personal history of breast cancer prior to the age of 50, personal history of ovarian cancer, firstdegree relative (i.e. mother, sister or daughter) with breast cancer below the age of 50, and first-degree relative (i.e. mother, sister or daughter) with ovarian cancer. Whether an individual had children was included in this study because previous studies conducted by our team and others have found that providing information to family members, particularly children, is one of the most important predictors of interest in being tested and/or intention to obtain genetic testing for a variety of hereditary cancers [15-19]. 
(1) How do you get information about health? (Probe for magazines, newspapers, Internet, friends, TV, other groups leading campaigns and initiatives such as pink ribbon campaigns, national Breast Cancer Awareness month, etc.)

(2) Which of these sources do you trust the most? Why?

(3) Do you use the Internet to get other types of information?

(a) What kinds? (Probe for use of Internet about health)

(b) How do you know if an Internet site is trustworthy?

(4) Do you discuss personal health issues with your family?

(a) If yes:

Which members of your family are you most likely to discuss personal health issues with?

Can you give me an example of a personal health issue that you recently discussed with family? (Probe to get a sense of who is 'family')

(b) No

(5) Do you discuss personal health issues with your friends?
(a) If yes: Can you give me an example of a personal health issue that you recently discussed with a friend?
(b) No

(6) Have you ever discussed cancer with your doctor?
(a) If yes:
Tell me about this discussion
Did the doctor bring it up?
Did you discuss risk factors?
Screening issues?
(b) No

(7) Have you ever discussed cancer with family?
(a) If yes: Tell me about this discussion

(b) No

(8) Have you ever discussed cancer with friends?
(a) If yes: Tell me about this discussion
(b) No

(9) Is written material a good way to reach Hispanic women from your community?
(a) Yes
(b) If no: What other ways would you suggest?
(Website, health fairs, TV or radio ads, etc.)

(10) In your opinion, where is the best place to provide written material? (Church, clinic, doctor's office, mail, health fair, etc.)

(11) Now l'd like you to review this pamphlet - If you saw this brochure somewhere, would you want to pick it up and read it?

(a) If yes, why?

(b) If no, why not?

(12) Was it easy to read?

(13) What do you think about the colors?

(14) What do you think about the font size?

(15) What do you think about the photos?

(16) What do you think about the tone of the pamphlet?

Additional questions specific to the brochure

(1) Would you want any of the following included:

(a) Information about the importance of testing from a health care provider?

Would you prefer the health care provider to be a doctor, genetic counselor, nurse or someone else?

Would you want him/her to be a Hispanic health care professional?

(2) Do you think the brochure should include a story or testimonial of a woman who had genetic counseling and testing for cancer?

(a) Would you want the story to be focused only on the woman or also include how testing affected her family? (Which members - husband, children, sisters?)

(b) Would you trust the information more if a known organization endorsed the brochure?

If yes: Could you give me an example of such an organization you would trust? (American Cancer Society, Lance Armstrong Foundation, Susan G. Komen for the Cure?)

(3) Do you have any other suggestions for this brochure?

Fig. 1. Interview guide.

\section{Analysis}

Three bilingual-bicultural research assistants transcribed the interviews verbatim. Results were analyzed using the transcripts and a combination of open and axial coding using a content analysis approach. Data were coded independently by at least 2 researchers, and an interrater reliability rate of $\geq 90 \%$ was achieved. Through content analysis, key themes were organized related to sources of health information, discussions of cancer and opinions on the mock brochure. Basic descriptive data related to demographic and clinical characteristics were summarized using descriptive statistics. $\chi^{2}$ tests were used to assess whether these characteristics varied by ethnicity (SPSS V 17.0). All tests were twosided and declared significant at the $5 \%$ level.

\section{Results}

Fifty-three women participated in the overall study, and 7 of these women also responded to additional questions about the mock educational brochure. Demographic, medical and cultural characteristics of the sample are shown in table 1 . The sample was approximately equally distributed across the age categories; the majority of respondents were married or living as married and had children. Educational attainment was split, with one third having not completed high school and one third having a college degree. Approximately half of the sample was employed at least part-time, one third had no health insur- 

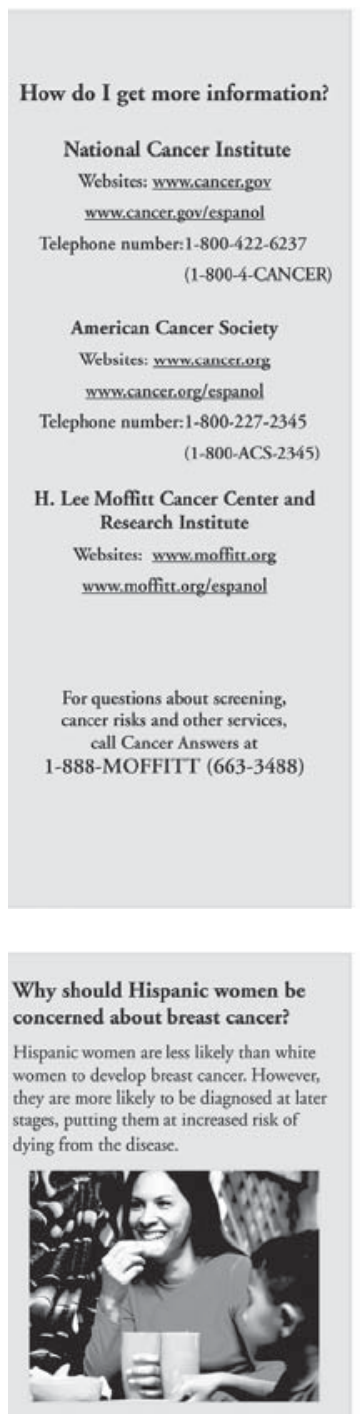

What is the role of genes/heredity in breast cancer?

- About 5-10\% of all cases of breast cancer are linked to changes in certain genes causing some women to be more likely to develop breast, and other types of cancer (i.e., ovarian cancer).

- Genes are instruction manuals for our bodies. They are the directions for building all the proteins that make our body function.

- Changes in the $B R C A l$ and $B R C A 2$ genes (short for breast cancer 1 and breast cancer 2) may be passed down in some families and are involved in many cases of

Fig. 2. Mock brochure.
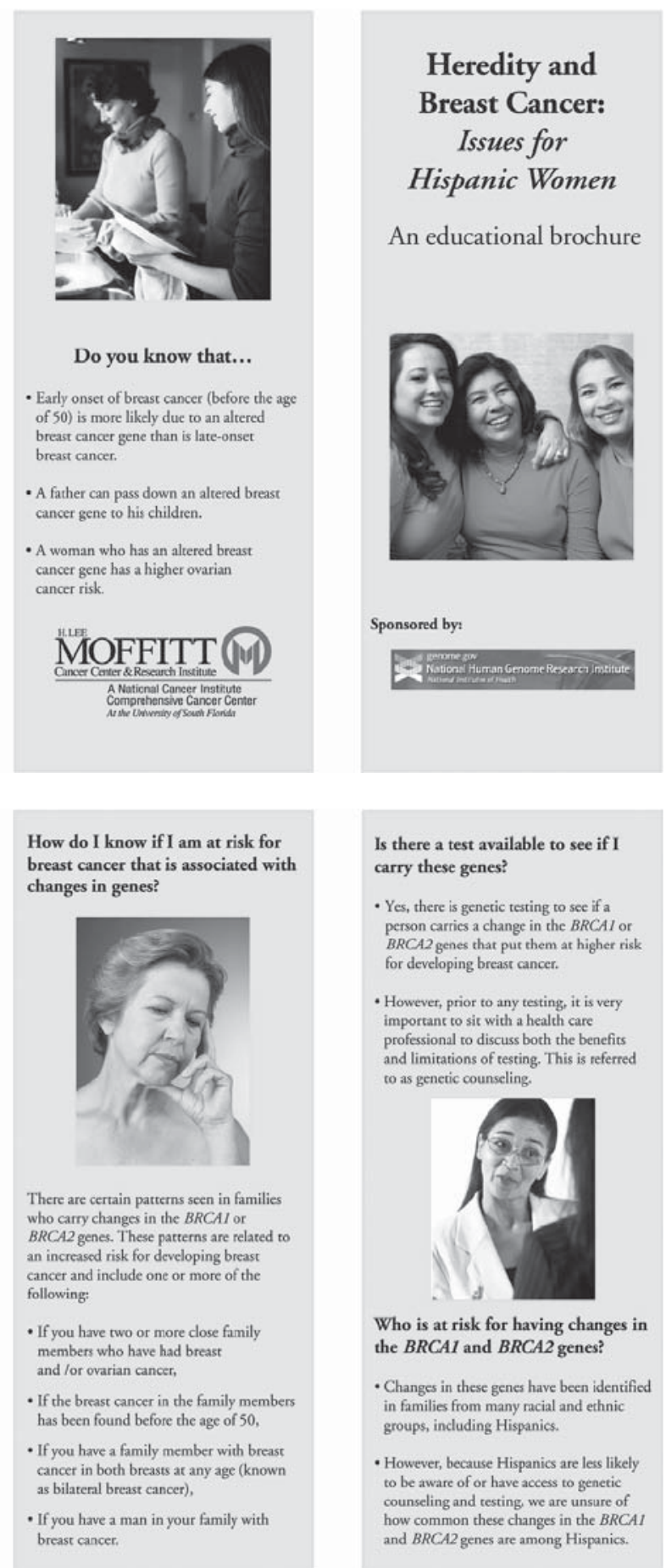

ance and cited Catholic as their religion, and half of the sample had an income of at least USD 20,000 a year. The majority of women had a first-degree relative with breast or ovarian cancer, and no personal history. Approximately two thirds of the sample were not born in the USA, but the same proportion had lived in the USA for at least 10 years.
There were no significant differences across the majority of demographic and clinical characteristics. However, Mexican women were more likely to report having less than a high school education, with $\chi^{2}(6, \mathrm{n}=53)=13.04$, $\mathrm{p}=0.04$, and having a first-degree relative with a diagnosis of ovarian cancer, with $\chi^{2}(2, n=40)=7.82, p=0.02$. 
Table 1. Sociodemographic, medical and cultural characteristics of the study participants $(n=53)$

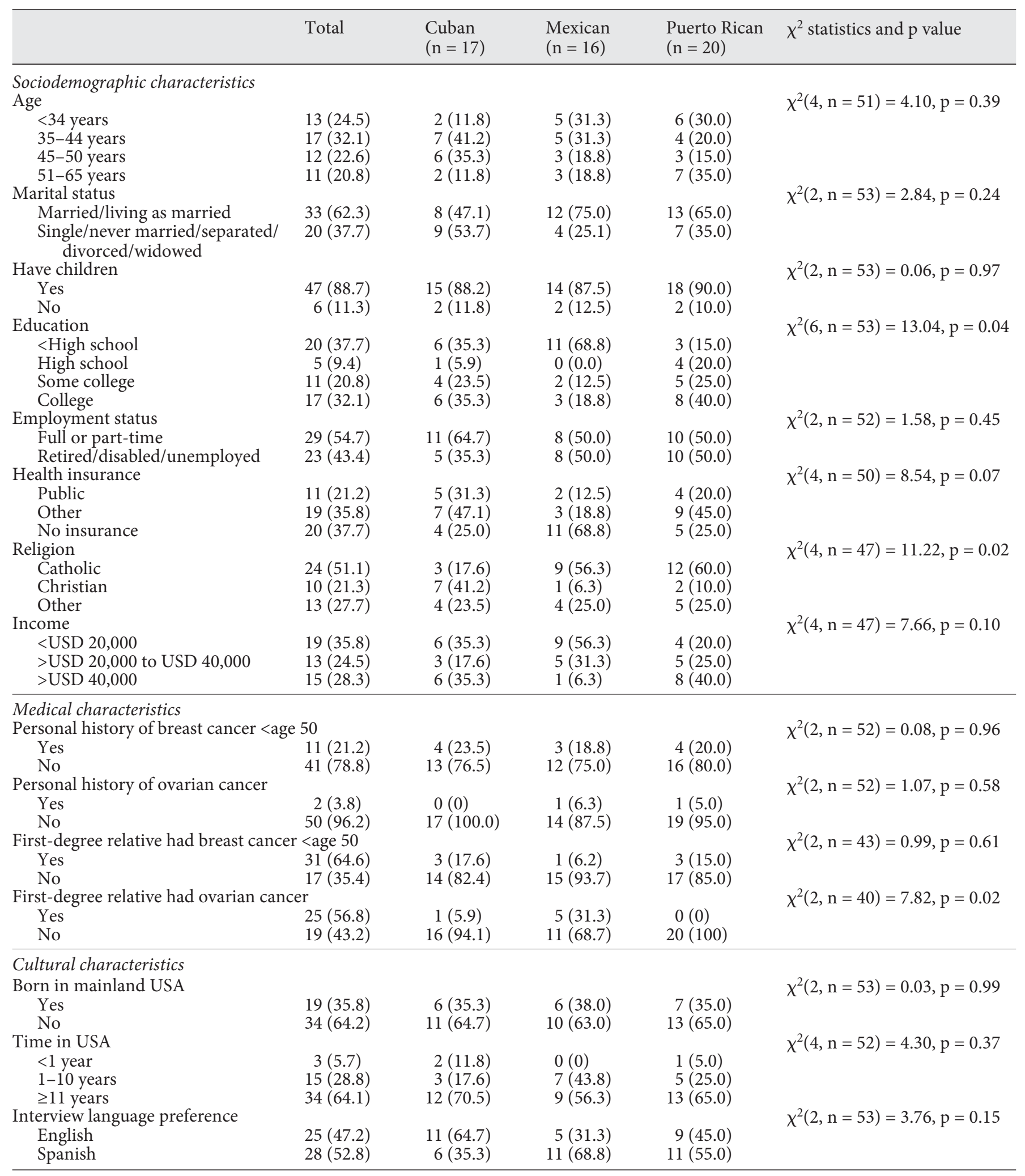

Numbers for each variable may not equal 53 due to missing data; percentages, given in parentheses, may not add up to $100 \%$ due to rounding error. 


\section{Sources of Health Information}

Respondents were asked how they preferred to get information about health. These responses varied across the three groups. The majority of Cuban women said their primary source of health information was their doctor. The second most likely source of information was the Internet followed by TV and magazines. However, within this group, several women reported being unsure where to go or how to get health information:

In my country they did give you information but here ... I do not know where to find it.

I do not have a doctor to ask for information and I have no health insurance either ... I do not know what to do.

The majority of Mexican women responded that, like the Cuban women, they received health information from a physician, though they also noted that this was likely to be a clinic or health department doctor and not a physician they saw on a regular basis. Their secondary source of information was health fairs, magazines and brochures:

Health fairs help us because we don't go to health centers because we have no money or resources ... sometimes we don't get treatment until it is too late.

No Mexican women in our study reported using the Internet for health information, and all said they did not have regular access to a computer. The majority of women in this group remarked they also did not have a regular source of health care and would not know how to get information on a health topic they were interested in or concerned about:

I only go to the doctor if I am feeling sick and I don't talk to him too much.

We don't ask for information (at the clinic) ... they look at us ... and we are ashamed.

The majority of Puerto Rican woman reported that their primary source of health care was print materials such as health magazines, brochures or newspapers. These same women reported using the Internet as their secondary source of health information. One third of the group of Puerto Rican women reported that a physician was their primary or only source of health care information.

\section{Discussion of Cancer}

Women were asked if they had ever discussed cancer or cancer risk with a physician. All but 2 of the Cuban women said they had previously discussed a family or personal history of cancer with a doctor, and all but 2 women reported they had this discussion only after a family member had been diagnosed with cancer, usually with a female relative:

When my sister passed away, I asked for information about how her disease may affect me.

We talked a lot about my mother's situation and what it meant for family history.

Because he knows my family history, we discussed cancer screenings.

Only half of the Mexican women reported discussing cancer with a doctor, typically after a personal or family member diagnosis:

I don't talk to the doctor much, only when I am sick ... but when he detected a lump above my breast ... cancer was mentioned.

I never talk about cancer with my doctor ... Until they had to test me for it because I had my menstruation for 6 months - then the doctor mentioned cancer.

The other half of the Mexican respondents said they had never discussed cancer with a physician or health care provider. No women in this group said a health care provider had discussed cancer screening with them:

Only when my kids were born they asked routine questions about family members with cancer ... But that is it.

The majority of Puerto Rican women reported that they had discussed cancer with a doctor. As with the other respondents, these discussions took place in relation to a personal concern about cancer or a recent family member's diagnosis. No women in this group reported their doctors discussing cancer screening with them: family.

Yes, I asked the doctor about cancer because it runs in my

Only after I was diagnosed with cancer did someone discuss it with me.

A nurse once told me that because my sister had breast cancer I should get a diagnostic test instead of screening. But I have not gone ... it's been years.

Respondents were asked if they had ever discussed cancer with a family member. The majority of women in all subethnicities said they had discussed cancer with their family, almost always after a family member had been diagnosed with the disease. Most women in all groups reported discussing with a female relative (e.g. sister, mother, aunt):

My sister and my mother had breast cancer and we talked about how they operated on them and removed their breasts.

When my sister was diagnosed with breast cancer, my family united and we were all able to discuss it.

Although Mexican women said they did discuss cancer in their family, about one third of these respondents 
also found that the discussions did not focus on the details of the cancer diagnosis or treatment, but instead on providing social and spiritual support to the person diagnosed.

Everyone is aware when there is cancer, but we pray for each other, we do not need to know the specifics.

It was not until my mother's death we learned she had ovarian cancer. We just knew she had the cancer and we took care of her.

A few women within each subethnicity said they never discussed or avoided discussing cancer in their family:

I have not wanted to touch that subject since we lost a sister ... talking about cancer is to remember her.

When I had a mastectomy, my family made hurtful comments about how my husband was a saint to stay with me. I do not want to discuss cancer with my family. I learned not to discuss.

\section{Opinions on Educational Materials}

Respondents were asked about their general perceptions of providing written materials (such as brochures and pamphlets) as a way to reach women in their community about health education topics. Next, they were specifically asked if written material was a good way to provide information about $\mathrm{HBOC}$.

The majority of Cuban women were positive, believing written materials were good ways to reach women in the community, for health in general and for HBOC-related information:

Yes, you have something in your hand and you can go to your doctor and ask 'what's this'.

Yes, it's something to carry and put in your purse and read when you can.

About one third of the Puerto Rican women said that written materials were not their first preference. These women said that they would rather learn about health information through discussions they viewed (such as TV media) or participated in (such as outreach education events):

I prefer to hear things first and then maybe read about them ... It's more reinforcing.

For this information (genetic testing), it seems very involved and I don't know how understandable it would be ... TV and health fairs are better.

About one half of the Mexican women thought written materials would be good for their community but were not their preferred method of health information. These women were likely to state that not all women in their community can read in Spanish or English. They further specified that Hispanic women do not like to read and prefer to discuss health information:
Charlas (health presentations) are a better way to reach women.

When people talk to you and you can ask questions, you understand it better.

Hispanic women don't like to sit down and read, so open seminars in a church or health center are better.

Written material is ok for people who can read, but charlas are better for those of us who don't know a thing and can't read.

The majority of Cuban women believed written materials were good for their community. The positive attributes of written materials for Cuban women focused on the ability of materials to provide follow-up information and additional resources:

A pamphlet can give directions or a phone number to call or a website.

It can catch your eye at a doctor's office and you may want to read it.

However, despite providing positive comments about the use of written materials, more than half of this group suggested that for other women (not themselves), written brochures may not be useful:

Reading is not the best way, it's better to speak to people about personal experiences.

We live in a time when not everyone can read ... and there are people who don't go to the doctor so they would not see a pamphlet in an office.

We (Hispanic women) are social - outreach events are better and attract more attention. Reading is solitary.

Respondents were asked where the best place would be to distribute written materials about HBOC for high-risk Hispanic women. Although women had made it clear in the previous question that written materials were not their first choice for educational materials about HBOC, all women in all subethnicities said they would like something to read after the initial information had been presented to them. Cuban women's first choice for placement of written materials was in a doctor's office, followed by health fairs and churches. Mexican women described health departments and clinics as the best place to provide brochures, followed by health fairs and schools. Puerto Rican women had markedly different responses in that their first choice was to have a brochure or pamphlet mailed to their home, followed by a doctor's office or a health fair.

The women were shown an example of a mock pamphlet targeted at Hispanic women, developed specifically by the research team. All women were optimistic about the brochure and had a variety of positive comments:

I like how it states where to go for more information. The Hispanic women on the front caught my eye. It's great because it tells you if you are at risk. 
All women liked the colors, font and tone of the brochure. Some women thought there should be more of the color blue in the brochure:

The colors were okay but I like blue better.

Most of the women in all subgroups liked the photos because the people looked familiar to them and because they reminded them of their family:

Photos indicate Hispanic women, which is very clear to pick up. Good, shows generations, shows a concerned woman.

The pictures made me think about my mom and sister.

However, women from each subethnicity had consistent and unique comments about the use of a brochure. Among the group of Cuban women, they tended to express their observation that Hispanic women do not want to discuss cancer and that the concept of hereditary cancer is an unappealing topic. Two women said they were offended by the portrayal of the risk statistics, comparing the risk of Hispanic women to that of White women. These women said: 'Hispanics can be White too, so what does this mean.' About half of the women said the risk information was difficult to understand:

Low-income Hispanic women don't want to know about the topic of cancer.

Hispanic women are very turned off by the title - hereditary and breast cancer.

I find it offensive [the risk statistics] just because we are Hispanic does not mean we are not White.

The majority of Mexican and Puerto Rican women were positive about the brochure, often reporting they were both drawn in and repelled by the title:

The first sentence catches my eye because it says Hispanic women are less likely than White to develop breast cancer, but we die from it more.

The word cancer in the title of anything is unattractive.

However, the majority of women in all three groups emphasized that a personal discussion about a topic related to cancer would be more far-reaching than a brochure:

Send someone to talk about the topic and make sure they can really speak to a person.

The participants were asked whether or not they would pick up the brochure if they saw it displayed somewhere. The majority of Cuban and Puerto Rican women said they would be likely to read the brochure if it were in a doctor's office or clinic. These women also thought they might discuss the brochure with their family: it up.

The Hispanic faces on the cover would make me want to pick

Hereditary Breast and Ovarian Cancer Genetics
The cover is very attractive and the title sounds important.

This makes it easy to bring home and talk to your sisters to figure out what you should do - does our family have risk?

However, the majority of Mexican women repeated their concerns that there are low reading levels among Mexican Hispanic women and that the word cancer is repelling:

I don't like to read and there are many in my community who cannot read.

I think we are traumatized by the word cancer ... Just seeing it makes us think of the worst.

After reaching saturation with this portion of the project, we included an additional 5 questions for the remaining women in the study $(n=7)$. Women were asked specifically what type of health care provider should present the information.

Cuban women thought the spokesperson should be a genetic counselor. Mexican women thought it should be a physician or female nurse. Next, they were asked if the health care professional should be Hispanic. All women agreed that this would not matter, the larger issue was whether or not the person spoke Spanish:

No preference as long as they speak Spanish.

The women were asked if the brochure should contain testimonials or stories about women who had genetic counseling and testing for cancer. The women differed by subethnicity about their preferences. Cuban women said they liked the personal stories in the brochure but were more interested in medical facts and clear understanding of who was at risk for HBOC:

Statistics and research are more important than a testimonial.

However, the majority of Mexican women preferred the individual stories and stated it made the information appeal to them on a personal level:

It would touch people's sensitive side. You think, that could be me and my family.

Next, women were asked if testimonials were to be included whether they should contain perspectives from other family members or just the person receiving genetic counseling. All women thought the focus should be on the woman herself but that family opinions were also important:

The family is important so that they know that they have risks too.

Respondents were asked if the brochure should include an endorsement by a professional organization. Only one woman said it was not necessary, the rest of the 
Table 2. Summary of key health information themes by subethnicity

\begin{tabular}{|c|c|c|c|}
\hline Content area & Cuban & Mexican & Puerto Rican \\
\hline Sources of health information & $\begin{array}{l}\text { (1) Primary care doctor } \\
\text { (2) Internet } \\
\text { (3) TV }\end{array}$ & $\begin{array}{l}\text { (1) Clinic doctor } \\
\text { (2) Magazines/brochures } \\
\text { (3) Health fairs }\end{array}$ & $\begin{array}{l}\text { (1) Print media } \\
\text { (2) Internet } \\
\text { (3) Primary care doctor }\end{array}$ \\
\hline Discuss cancer with doctor? & Yes, after personal/family diagnosis & $\begin{array}{l}\text { Sometimes, after personal/family } \\
\text { diagnosis }\end{array}$ & Yes, after personal/family diagnosis \\
\hline Perception of written materials? & $\begin{array}{l}\text { Positive, but prefer to hear or } \\
\text { participate in discussion }\end{array}$ & $\begin{array}{l}\text { Prefer to hear or participate in } \\
\text { discussion }\end{array}$ & $\begin{array}{l}\text { Positive, want follow-up informa- } \\
\text { tion with Internet or phone number; } \\
\text { prefer discussions }\end{array}$ \\
\hline Best place to display materials & $\begin{array}{l}\text { Doctor's office } \\
\text { Health fairs } \\
\text { Church }\end{array}$ & $\begin{array}{l}\text { Clinic } \\
\text { Health fairs } \\
\text { Schools }\end{array}$ & $\begin{array}{l}\text { Mailed to home } \\
\text { Doctor's office } \\
\text { Health fair }\end{array}$ \\
\hline Spokesperson for HBOC information? & Genetic counselor & Female nurse & Doctor \\
\hline Want personal stories of $\mathrm{HBOC}$ ? & $\begin{array}{l}\text { Maybe, statistics and research better } \\
\text { information }\end{array}$ & Yes, makes interesting & Yes, with photographs \\
\hline
\end{tabular}

Italicized content areas indicate differences between the subethnicities.

women agreed but had varied opinions about which organization. Some thought it should be the cancer center while others thought it should be the American Cancer Society. Key themes for each of the topics are shown by subethnicity in table 2. Marked differences in responses are italicized.

\section{Discussion}

Overall, the results indicate that there are both similarities and differences across at-risk Hispanic subethnicities with regard to preferences for the presentation and content of health information regarding HBOC. The concept of hereditary cancer informational needs has not been well addressed in the literature, and these results indicate the need to examine subethnicities within Hispanic populations. While all groups were similar in their information seeking with regard to discussing cancer with a health care provider and within their family, the content of these discussions varied. Other research has shown that Hispanics as a whole often have cultural taboos about discussing cancer with families and are reluctant to bring up cancer-related issues with a health care provider [20]. Still other research on Hispanic health shows varied levels of discussion about a cancer diagnosis or prevention within families [21-23]. Some Hispanic women may prefer not to discuss cancer with family members at all $[11,24]$.

The majority of Mexican women and about one third of the Cuban and Puerto Rican women indicated that written material was not their preferred method to receive health information and that they would desire a setting in which the information was discussed, either as a group in a 'charla' or with the ability to call someone on the telephone for a follow-up or in-depth discussion. These results are similar to that of Talosig-Garcia and Davis [23], who confirm in their study on the assessment of the use of the National Cancer Institute's website (www. cancer.gov) that minority breast cancer patients were using the Internet for cancer-related information at a very low rate. Armstrong et al. [25] also confirm low rates of using the Internet or health care providers for information about HBOC testing. Their study also indicates that women of Hispanic origin were the least likely to take up genetic testing, as compared to Whites and African-Americans. Other studies examining preferences for health information among Hispanic subethnicities also 
indicate that face-to-face discussion and visual media are preferred over written text [26-28].

Our data indicate that health education promotions from a local clinic are Mexican women's first choice for receiving information about $\mathrm{HBOC}$, and the first choice for Puerto Rican women is for it to be mailed to their home. While all groups mentioned a health fair as one of their top three choices, only Cuban women noted the use of churches and only Mexican women noted a preference for this information through their child's school. While preferred methods of receiving health information by Hispanic subethnicity have not been explored in other studies, these data seem to confirm the experiences of other researchers that recruitment efforts for participation in cancer screening varied by subethnicity $[9,10,24]$.

All groups said that they would read a brochure about HBOC but Mexican women thought the reading level of currently available health-related brochures, including the one developed for this project, was too high. Additionally, Mexican women indicated that reading was not their preferred way to receive health information. Health literacy is a key issue in designing and promoting effective interventions and strategies with underserved populations. In the few studies that have examined health literacy among Hispanic women, the majority find that Mexican women often have lower rates of literacy [29-31].

Cuban women preferred a genetic counselor as the spokesperson while Mexican women favored a physician or female nurse. Identification of a spokesperson for cancer-related health messages has not been well explored but studies that have examined preferences among Hispanics for other health issues have shown varied preferences, depending on the topic [26-28, 32].

All women preferred some level of personal stories in the brochure describing women who had pursued genetic counseling and testing, but the women varied in their desire for the amount of space devoted to a personal story relative to medical facts and statistics versus photographs. The use of personal stories as both a motivational tool and facilitator of understanding health messages has shown high levels of preferences by Hispanic women [33-35]. Additionally, the recognition of the role of family and Hispanic culture has also led to more efficacious health promotions among Hispanic women [26-28, 36].

\section{Limitations}

As with all qualitative studies, the results of this are not generalizable to other communities or populations. Additionally, our sample was recruited from the Tampa Bay area and may not be representative of Hispanics from other regions of the USA. However, our study is among the first to include representation from three of the major Hispanic subethnic groups in the USA. The overall sample size for each subethnic group was small; thus, any conclusions related to differences by subethnicity must be replicated in a larger population. Finally, only a small subset of women from the Cuban and Mexican subethnic groups participated in the additional questions about the educational brochure, but these data do provide some clues about areas for further exploration in larger samples.

\section{Conclusion}

There are similarities and differences in the ways in which Mexican, Puerto Rican and Cuban women prefer to receive information about HBOC. The similarities and differences appear to be related to the ways in which these groups currently perceive and utilize health care services. While most of these differences are subtle, they indicate the likelihood of a Hispanic woman having a successful receipt of information about $\mathrm{HBOC}$, and this leading to informed decision-making may be more likely to occur when the information is tailored to her cultural preferences.

\section{Acknowledgements}

Funding for this project was provided by grant 1 R03 HG003887 from the National Human Genome Research Institute. The work contained within this publication was supported in part by the Survey Methods Core Facility at the H. Lee Moffitt Cancer Center and Research Institute.

References

1 Projections of the resident population by age sex, race, and Hispanic origin: 1999 to 2100. Washington, US Census Bureau, Population Projection Program, Population Division (NP-D1-A), 2000.

2 Ramirez R, de la Cruz P: The Hispanic population in the United States: March 2002, 2003. Washington, US Census Bureau, United States Department of Commerce, 2003.

3 Brodie M, Valdez J, Levin R, Suro R: National survey of Latinos: summary of findings. Menlo Park, Henry J. Kaiser Family Foundation and Pew Hispanic Center, 2002.

4 Buki LP, Feigal BM, Carillo IY: Are all Latinas the same? Perceived breast cancer screening barriers and facilitative conditions. Psychol Women Q 2004;28:400-411. 
5 Glanz K: Cancer in Women of Color Monograph. Bethesda, National Cancer Institute, 2003.

6 Hunt LM, Comer B: Should 'acculturation' be a variable in health research? A critical review of research on US Hispanics. Soc Sci Med 2004;59:973-986.

-7 Zambrana RE, Fox SA, Gutierrez-Mohamed ML: Use of cancer screening practices by Hispanic women: analyses by subgroup. Prev Med 1999;29:466-477.

8 John EM, et al: Prevalence of pathogenic BRCA1 mutation carriers in 5 US racial/ethnic groups. JAMA 2007;298:2869-2876.

9 Weinick RM, et al: Hispanic healthcare disparities: challenging the myth of a monolithic Hispanic population. Med Care 2004;42: 313-320.

10 Lara M, et al: Acculturation and Latino health in the United States: a review of the literature and its sociopolitical context. Annu Rev Public Health 2005;26:367-397.

11 Ramirez AG, et al: Hispanic women's breast and cervical cancer knowledge, attitudes, and screening behaviors. Am J Health Promot 2000;14:292-300.

12 Cheong PH: Health communication resources for uninsured and insured Hispanics. Health Commun 2007;21:153-163.

13 Guest G, Bunce A, Johnson L: How many interviews are enough? Field Methods 2006;18: 59-82.

14 Kvale S: Interviews: An Introduction to Qualitative Research Interviewing. London, Sage, 1996.

15 Kinney AY, et al: Knowledge, attitudes, and interest in breast-ovarian cancer gene testing: a survey of a large African-American kindred with a BRCA1 mutation. Prev Med 2001;33:543-551.

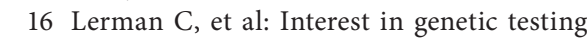
among first-degree relatives of breast cancer patients. Am J Med Genet 1995;57:385-392.
Kinney AY, et al: Attitudes toward genetic testing in patients with colorectal cancer. Cancer Pract 2000;8:178-186.

18 Ulrich CM, et al: Genetic testing for cancer risk: a population survey on attitudes and intention. Community Genet 1998;1:213222.

19 Vadaparampil ST, Azzarello L, Pickard J, Jacobsen PB: Intention to obtain genetic testing for melanoma among first degree relatives of melanoma patients. Am J Health Educ 2007;38:148-155.

20 Ashing-Giwa KT, et al: Understanding the breast cancer experience of women: a qualitative study of African American, Asian American, Latina and Caucasian cancer survivors. Psychooncology 2004;13:408-428.

21 Mitchell JL: Cross-cultural issues in the disclosure of cancer. Cancer Pract 1998;6:153160.

22 Puschel K, et al: Factors related to cancer screening in Hispanics: a comparison of the perceptions of Hispanic community members, health care providers, and representatives of organizations that serve Hispanics. Health Educ Behav 2001;28:573-590.

23 Talosig-Garcia M, Davis SW: Informationseeking behavior of minority breast cancer patients: an exploratory study. J Health Commun 2005;10(suppl 1):53-64.

24 Suarez L, et al: Social networks and cancer screening in four US Hispanic groups. Am J Prev Med 2000;19:47-52.

25 Armstrong K, et al: Racial differences in the use of BRCA1/2 testing among women with a family history of breast or ovarian cancer. JAMA 2005;293:1729-1736.

26 Prue CE, et al: But I've already had a healthy baby: folic acid formative research with Latina mothers. J Womens Health (Larchmt) 2008; 17:1257-1269.
27 Quinn GP, et al: Promoting pre-conceptional use of folic acid to Hispanic women: a social marketing approach. Matern Child Health J 2006;10:403-412.

28 Quinn GP, et al: Evaluation of educational materials from a social marketing campaign to promote folic acid use among Hispanic women: Insight from Cuban and Puerto Rican ethnic subgroups. J Immigr Minor Health 2009;11:406-414.

29 Lindau ST, et al: The association of health literacy with cervical cancer prevention knowledge and health behaviors in a multiethnic cohort of women. Am J Obstet Gynecol 2002; 186:938-943.

30 Lindau ST, et al: Improving rates of cervical cancer screening and Pap smear follow-up for low-income women with limited health literacy. Cancer Invest 2001;19:316-323.

-31 Scott TL, et al: Health literacy and preventive health care use among Medicare enrollees in a managed care organization. Med Care 2002;40:395-404.

32 Sheppard VB, et al: If you build it, they will come: methods for recruiting Latinos into cancer research. J Gen Intern Med 2005;20: 444-447.

33 Katz JN: Patient preferences and health disparities. JAMA 2001;286:1506-1509.

34 Larkey LK, et al: Hispanic cultural norms for health-seeking behaviors in the face of symptoms. Health Educ Behav 2001;28:6580.

35 Otero-Sabogal R, et al: Access and attitudinal factors related to breast and cervical cancer rescreening: why are Latinas still underscreened? Health Educ Behav 2003;30: 337-359.

36 Luquis RR, Villanueva Cruz IJ: Knowledge, attitudes, and perceptions about breast cancer and breast cancer screening among Hispanic women residing in South Central Pennsylvania. J Community Health 2006;31: $25-42$. 